\title{
Limits to Stability
}

\author{
ALAN COTTEY \\ University of East Anglia, Norwich, United Kingdom
}

\begin{abstract}
The author reflects briefly on what limited degree of global ecological stability and human cultural stability may be achieved, provided that humanity retains hope and does not give way to despair or hide in denial. These thoughts were triggered by a recent conference on International Stability and Systems Engineering.
\end{abstract}

I recently attended a conference on International Stability and Systems Engineering. [1] As often occurs with academic or mainly academic conferences a large number of organisations and individuals had an 'in conjunction with', a sponsoring or a committee member role. The principal organisers were INSYTE (Centre for Information Systems and Technoculture) at the Waterford Institute of Technology, Ireland. Other organisations involved included IFAC (the International Federation for Automatic Control), several technical committees of IFAC, principally TC 9.5 (International Stability), and SWIIS 2012 (Supplementary Ways of Improving International Stability). The conference included a special session on Roles and Responsibilities of Scientists and Engineers in Achieving a Just and Sustainable World. And there is more, which you do not need or want to know. So what is this rather unmemorable set of acronyms and titles about?

The great majority of engineers and scientists (most other academics and professionals as well) get on with applying their hard-won specialised expertise and earning a living and status. Shortly before his death, the physicist, astronomer and engineer Martin Ryle, known for the development of aperture synthesis radio astronomy wrote of the attitude of scientists to affairs outside their own narrow field of research

"Most simply do not want to think about these things - and like most of the public believe or accept - that 'the experts know best'."

A few professionals (I will restrict the following discussion to professionals, without denying the role of all other people) in all areas put significant effort into looking beyond their specialism to see the bigger social setting, to which their technical contributions are small but vital parts. To understand the complex array of concepts mentioned above, one has to go to history. The bipolar cold war between the United States (US) and the Soviet Union (SU) started even before the end of 
the second World War. During the following decades the arsenals of thermonuclear weapons escalated to extraordinary levels, so that the destruction of humanity became a real possibility - and not just by accident or miscalculation. In the 1960s to 1980 s the acronym MAD, standing for Mutually Assured Destruction, was widely used, and not wholly in a rhetorical way.

Prominent among engineers reacting to this danger was Harold Chestnut [2] whose distinguished career in control engineering brought him, through active involvement in the formation of the International Federation of Automatic Control, into close contact with the political realities of international relations. He gave his later years (the 1980s and '90s) to methods of improving international stability. His efforts included the creation of the SWIIS Foundation, devoted to identifying and implementing "supplemental ways to improve international stability". I interpret 'supplemental ways' to mean that engineers could use their specialised expertise to assist diplomats and politicians with technical development and advice needed for the improvement of international stability.

In those times nation-states, preeminently the US and SU, were considered to be the main actors in world politics, hence the salience of the word International in the opening paragraph above. Today, nation-states are seen to be one kind among other powerful actors. An opposing view to the internationalist one is that nation-state policies are strongly influenced by lobbying by large multination corporations and plutocrats. Importantly, the neo-liberal economic agenda holds sway world-wide, notably through the power of the World Trade Organisation, the World Bank and the International Monetary Fund. From this point of view, the salience of 'International' mentioned above seems dated but in fact it is only the names that are unchanged. Thinking has moved on. The conference reflected the increased awareness of global ecological instability. As for military instability, it has not gone away but its nature has changed, for example through advances in robotics, a topic which came up at the conference.

The usage in the descriptions of the conference and the discourse at the conference and in society at large bespeak a great longing for stability. Obviously this relates to the justified fear of catastrophic ecological change. Also widespread, and understandable albeit less justifiable, are psychological defences such as denial and inattention. In engineering it is known that stability does not have to mean a completely static situation. It is usually allowed that variations occur and a stable system oscillates about a homeostatic state, or a slowly varying state. The converse, instability, is when a small change grows and leads to a totally new state, perhaps at a more-or-less exponentially increasing rate, or even as a step function (a catastrophe, or 'fall from a cliff edge'). The matter is 
however not as simple as a clear-cut division between stability and instability, even in engineering but especially in political and cultural affairs and in the natural world. In the earth's evolution there have been intervals of relative stasis, intervals of sudden change and indeed of change on all timescales. Although we tend to think of our present times as special, and the present ecological state of the world is indeed more unstable than it has been for many millennia, it is sensible to try to look at the situation calmly, without denial, fatalism or panic. I argued in an earlier column [3] for a bold enlargement of our temporal horizons, forward as well as backward. With this larger perspective we may be able to adapt to the ever changing conditions with justice for the deprived and without rancour against those who have made errors out of ignorance or hubris. That, perhaps, is as near as we may get to stability. With this point of view goes an attitude of modesty in respect of Policy, which should be formulated with constant awareness of the likelihood of unintended consequences. Policy may be ambitious but not grandiose. The progress of policies should be closely monitored and this should include assessments of the dangers of lock-in, be it technological or social.

Education came up frequently at the conference, of course, partly because the participants were mostly employed in education and partly through presentations of education research. Many professional educators are indeed promoting sustainability, with the aim of contributing to a more stable world or at least avoiding catastrophic instability. These efforts are normally reformist. Generally absent is a radical analysis, critiquing, for example, the existing commitment, deeply embedded in society, to 'property before people' and to unlimited accumulation. No doubt all professionals are at risk of being influenced by parochialism, no matter how intellectual or philosophical their subject or their personal approach. Education is no exception and so it is hard for educationists to entertain the question 'is education part of the problem as well as part of the solution'. Having retired from paid education, I find it easier to put this question and to answer that the problematic aspects of education, in respect of achieving a just and sustainable world, are great. Education has been commoditised to a large and increasing extent. Sustainability education which does not address issues of hierarchy and unlimited accumulation is destined to remain as ineffective as it has been to date. One may ask - does a new person born into the world need much at all by way of institutional education, especially compulsory and semi-compulsory schooling? Is it wise to segregate young people, for a significant part or their early lives, away from normal society, in special institutions? Is such 'education' destructive of a humane, social skill-sharing that could be part of everyone's life-long experience? 
Few are willing even to consider radical transformation. Most are suspicious, having been subjected to centuries of propaganda to the effect that such ideas are likely to destroy the good that has been developed over many millennia. The ground under the long debate between these two points of view has shifted in recent times. The planet's ecology is now subject to multiple assaults and is undergoing change more rapid than has occurred for many millennia. So reformism is no longer an option. Many appear to accept this, perhaps subliminally. Has any potentially important Summit of major nation-states been treated by the public and the media, and perhaps even the participants themselves, with such weariness and cynicism as the 2012 United Nations Conference on Sustainable Development, informally known as Rio+20 [4]? If this analysis is correct, the ecological state of the world and the state of human civilisation will decline yet further - for a while. Yet it will not be long before the reality of these declines become undeniable. At that stage, humanity may possibly respond to a wake-up call. There may be a sea-change in human culture and a modest lifestyle for all may become the dominant ideology. The several centuries long era of possessive market society will in any case come to an end. The only question is, will it evolve into a sustainable culture or decay into a loss of the cultural gains of the last few millennia?

In this grim situation it is necessary to hold onto some hope but it must be tempered by realism. Much as it may be tempting, it is wrong to hope or aim for stability in any strong sense. The best that is worth working for is change that is bearable, with positive cultural elements and, if possible, no catastrophically rapid ecological change. An example in line with this thinking is provided by Colin Baglin [5]. He argues for modest, cautious geoengineering schemes, not as a substitute for reducing carbon emissions (which has its effect only on a long time-scale) but as a way of ameliorating the current worsening situation on a shorter (decade) time-scale.

\section{Notes}

[1] SWIIS 2012 (no date) International Stability and Systems Engineering. http://swiis2012.com

[2] IEEE global history network (no date) Obituary of Harold Chestnut. http://www.ieeeghn.org/wiki/index.php/Harold_Chestnut (accessed 21 June 2012).

[3] Alan Cottey (2012) Logarithmic time: its role in current culture and education, Policy Futures in Education 10 (2), 234-236.

[4] United Nations (no date) Rio+20 United Nations Conference on Sustainable Development. 
http://www.uncsd2012.org (accessed 21 June 2012).

[5] Colin Baglin (2012) Fixing the Climate, Physics World, 25 (6), 16-17.

ALAN COTTEY is a Fellow at the University of East Anglia. He is a physicist who also taught on 'science, values and ethics'. He believes that it is desirable that all, specialists or not, give long-term attention to current ecological, including social, conditions. Correspondence: Dr A A Cottey, School of Chemistry, University of East Anglia, Norwich NR4 7TJ, UK (a.cottey@uea.ac.uk)

[Author manuscript (postprint) of Policy Futures in Education (2012) Vol 10 Issue 6, pp 734 - 736 DOI: $10.2304 /$ pfie.2012.10.6.734 http://dx.doi.org/10.2304/pfie.2012.10.6.734 ] 